\title{
BMJ Open Evaluating stress, satisfaction and the associated influencing factors of participants in cancer clinical trials: a cross-sectional study in China
}

Shiyu Jiang, ${ }^{1}$ Peng Liu, ${ }^{1}$ Sheng Yang, ${ }^{1}$ Jianliang Yang, ${ }^{1}$ Dawei Wu, ${ }^{1,2}$ Hong Fang, ${ }^{2}$ Yan Qin, ${ }^{1}$ Shengyu Zhou, ${ }^{1}$ Jianping Xu, ${ }^{1}$ Yongkun Sun, ${ }^{1}$ Hongnan Mo, ${ }^{1}$ Lin Gui, ${ }^{1}$ Puyuan Xing, ${ }^{1}$ Bo Lan, ${ }^{1}$ Bo Zhang, ${ }^{1}$ Le Tang, ${ }^{1}$ Yan Sun, ${ }^{1,2}$ Yuankai Shi ${ }^{1,2}$
To cite: Jiang S, Liu P, Yang S, et al. Evaluating stress, satisfaction and the associated influencing factors of participants in cancer clinical trials: a cross-sectional study in China. BMJ Open 2019;9:e028589. doi:10.1136/ bmjopen-2018-028589

- Prepublication history and additional material for this paper are available online. To view these files, please visit the journal online (http://dx.doi. org/10.1136/bmjopen-2018028589).

Received 15 December 2018 Revised 5 April 2019 Accepted 29 April 2019
Check for updates

(C) Author(s) (or their employer(s)) 2019. Re-use permitted under CC BY-NC. No commercial re-use. See rights and permissions. Published by BMJ.

For numbered affiliations see end of article.

Correspondence to Professor Yuankai Shi; syuankai@cicams.ac.cn

\section{ABSTRACT}

Objectives Patients' stress and satisfaction concerning cancer clinical trials (CCT) may affect study accrual and quality. Our study aimed to evaluate stress and satisfaction in CCT and the influencing factors.

Design Cross-sectional analysis done by a questionnaire after informed consent.

Setting Cancer Hospital, Chinese Academy of Medical Sciences.

Participants 199 CCT participants. Primary and secondary outcome measures self-assessed stress and satisfaction in CCT.

Results Among 199 participants, 83.9\% would join CCT again; $72.9 \%$ had enough time to decide on trial participation; $73.9 \%$ claimed complete awareness of CCT; $3.5 \%$ doubted CCT's significance and scientific quality; $33.2 \%$ deemed CCT time-consuming; $73.9 \%$ scored satisfaction $\geq 9 / 10$; and $25.6 \%$ claimed moderate to severe stress. Positive factors for satisfaction were enough decision time ( $0 R=0.36, p=0.0003)$, better impressions of doctors $(\mathrm{OR}=0.41, \mathrm{p}=0.047)$ and less time-consuming trials $(0 R=0.43, p<0.0001)$. Individuals with more prior uninsured medical expenses $(0 R=1.23, p=0.026)$, less time consumption $(0 R=2.35, p<0.0001)$ and more tests in CCT ( $0 R=0.64, p=0.035)$ were less likely to experience stress. Phase III study participants bore less stress than phase II $(0 R=0.29, p=0.032)$ but more than phase I $(\mathrm{OR}=1.18, \mathrm{p}=0.009)$.

Conclusions Our study addressed factors influencing CCT participants' stress and satisfaction. We suggested measures to improve patients' experiences in CCT. Trial registration number NCT03412344; Pre-results.

\section{INTRODUCTION}

Advances in medical oncology field have been made with the understanding of cancer biology, the development of innovative drugs and the facilitation of clinical pipelines, which depends on cancer clinical trials (CCT) and the voluntary participation of research participants to move forward. In general, the pace and extent of clinical trials in China has been booming. Promoted by The Healthy China
Strengths and limitations of this study

- This is a cross-sectional study limited in a single centre of excellence.

- This study provided a summary of Chinese trial participants' perception towards cancer clinical trials which has not been previously available.

- The reliability for stress and satisfaction evaluation is limited based on one item for each.

- Due to the cross-sectional nature and self-designed questionnaire, indicators and experience could have been affected by bias.

- Patients declining to join our study were not surveyed which limits the result from generalising to a broader population.

2030 plan and the 13th national 5-year plan, the approval and launch of innovative drugs have been accelerated, thus boosting biomedical innovation. According to China Food and Drug Administration statistics, from 2008 to 2016, the number of class 1.1 and new class chemical drugs submitted for evaluation has increased 4.6 times. Supportive policies, enhanced innovation and development of the Chinese pharmaceutical industry have accelerated the speed of clinical trials and optimised research development. ${ }^{1}$

Cancer has become a devastating disease and a major challenge in China, with an estimated 4292000 new cancer cases and 2814000 cancer deaths in China in $2015 .^{2}$ According to statistics from the National Central Cancer Registry, cancer is the first leading cause of death in China, with the crude mortality rate of 160.1 and 155.8 per 100000 people in urban and rural China, respectively. ${ }^{3}$ Improvement of clinical cancer care requires a concerted effort and commitment throughout the whole chain of 
biomedical innovation, which contributes to increasing attention on CCT.

Studying satisfaction and stress during clinical trial participation could contribute to raising participants' satisfaction and improving their psychological status during trial participation. Abundance of data regarding psychological status and quality-of-life of cancer patients have emerged, both in real-life and in clinical trial setting, demonstrating different psychological status in various cancer population or under some specific intervention. ${ }^{4-12}$ Despite the emphasis on the the relationship between intervention and patient psychological distress and quality-of-life in clinical trials, ${ }^{10-12}$ to date, the factors contributing to patients' satisfaction and distress during participation have not been fully addressed. Previously, some factors including common barriers (such as transportation, financial burden and mistrust in researchers), social support, cultural appropriateness, education level and the design of the CCT have been demonstrated to correlatewith trial participation. ${ }^{13-26}$ Regarding design of clinical trials, study phase is the most determining factor. Phase I clinical trials, also known as 'first-in-man studies', dedicate to determine safety, toxicity and the safe dosage range of tested drug. Phase II trials aim to assess the efficacy and further evaluate drug safety in a larger group of patients, while phase III trials are larger and use randomised, controlled approaches to determine the value of a treatment in clinical practice. In order to maximise patient benefit and enhance speedy recruitment in clinical trials, it is significant to analyse patients' real-world satisfaction and stress in trial participation and the influencing factors.

A better understanding of the concerns and perceptions could enhance patient enrolment and experience in CCT. Published evidence has identified a variety of factors affecting enrolment, including demographic characteristics, socioeconomic status, individual perceptions and psychological and racial attributes-however, these results may not be applicable to the Chinese population, which has different sociocultural backgrounds. ${ }^{20} 2728$ Actually, factors such as insufficient communication between hospital staff and patients, inadequate medical service quality, heavy workload and flawed healthcare system have deteriorated the unpleasant doctor-patient relationship in China. ${ }^{29-32}$ In this context, studying the perceptions, satisfaction and psychological status as well as addressing the underlying concerns of patients are of particular significance, which could contribute to increasing participants' satisfaction, optimising their experience and to an extent relieving doctor-patient relationship in CCT. Besides, it could also influence the compliance of participants, their willingness to participate a second time, the enrolment of other patients and the quality and speed of clinical trials in a positive way. ${ }^{33} 34$ Thus, within the setup of a tertiary care hospital, we evaluated patient perception, satisfaction and stress in the CCT and explored the influencing factors in the hope of raising participants' satisfaction, improving their psychological status during trial participation and providing useful information for cancer patient education, especially in the clinical trial field.

\section{MATERIAL AND METHODS Study design}

This cross-sectional study ran from April 2017 to April 2018, in the National Cancer Center/National Clinical Research Center for Cancer/Cancer Hospital, a tertiary hospital in China. The inclusion criteria were as follows: aged 18 years and older, having participated in or under treatment/follow-up in a CCT and ability to understand and complete the questionnaire independently, or with the help of a relative or staff member in the oncology department. Participants with physical, cognitive or mental disability assessed by the investigators through the interview were excluded. On patients who met the inclusion criteria came to our institute for scheduled treatment or onsite follow-ups, the investigators (not the principal investigators of the CCT the patient participated) explained the aim of this study and invited patients to join. After informed consent was provided without patient signature, a 40-item questionnaire was delivered in person without personal identifier so that confidentiality was preserved.

\section{Questionnaire and data measures}

The questionnaire developed and used in this study aimed to assess the perception, stress and satisfaction of CCT participants, and factors impacting their stress and satisfaction For the purpose of questionnaire design, we searched for papers on the use of 'stress OR depression OR distress' and 'satisfaction' in cancer patients, as well as factors influencing patient enrolment. Factors previously reported to be correlated with participation decision, patient psychological distress and satisfaction degree were included into questionnaire design and improved it through discussing with 10 experienced investigators at our institute. The final form of the questionnaire was approved by all investigators. The respective questionnaires did not ask for names or addresses of participants. It was written in Chinese, the native language of the participants. The final questionnaire consisted of 40 questions and was divided into 3 parts. The first section comprised mostly demographic information, whereas the second section explored different aspects of the participants' perception, stress and satisfaction in CCT. The third section referred to other potential information related to conducting the trial. The indicators identified and included in the survey were as follows.

\section{Demographic indicators and trial characteristics}

The demographic indicators were age, gender, cancer subtypes, occupation, yearly household income per person, education and the uninsured medical expenses on cancer. Additional information included number of times participating in a trial, patient insurance types, trial 


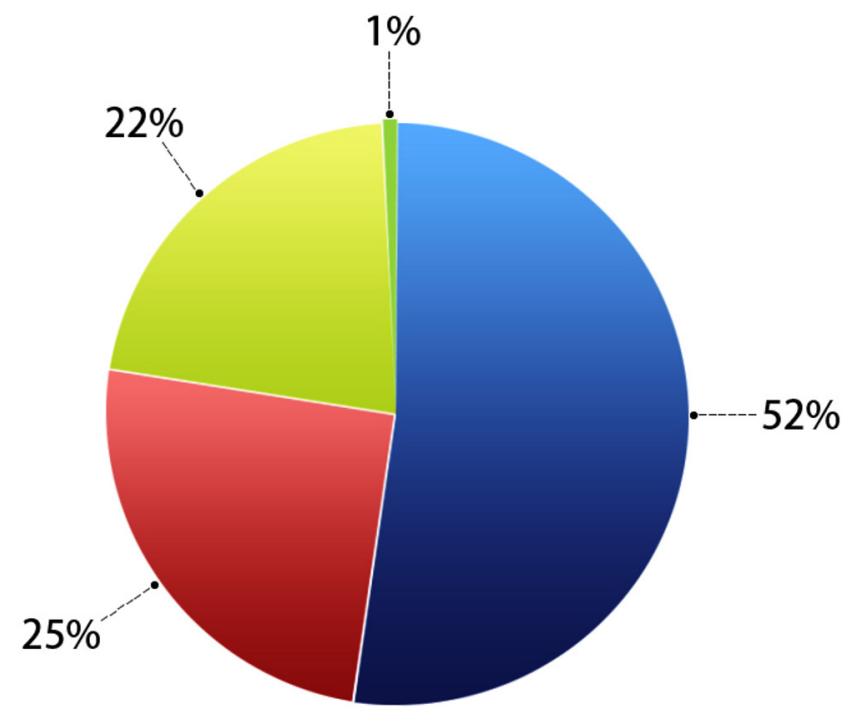

- I'm severely stressed so that I want to drop out.

- I'm stressed with intent to quit.

- I'm moderately stressed with acceptance.

\section{I feel mild stressed.}

\section{I'm not stressed at all.}

Figure 1 Evaluation of self-assessed stress level of Chinese patients participating in cancer clinical trials.

phase, travel distance and time spent travelling and time for decision-making before trial participation.

\section{Satisfaction indicators and stress indicators}

An 11-point scale, from strongly satisfied (score 10) to strongly dissatisfied (score 0), was used for measuring patient self-reported satisfaction in their trial participation. Their self-reported stress was scored on a five-level ordinal scale, from 'not stressed at all' to 'severely stressed so that I want to drop out now' (figure 1).

\section{Perception towards CCT and clinical practitioners}

The impression towards clinical trial researchers, the clinical research coordinator, clinical practitioners and previous oncologists were measured using a 5-point ordinal response scale, from extremely good to strongly dislike. The perceived purpose of CCT by patients, the benefit of CCT and the willingness to participate in CCT again were also collected.

\section{Statistical analysis}

Cronbach's $\alpha$ value was determined as an indicator to assess the internal consistency of the questionnaire. In this study, the Cronbach's $\alpha$ value was 0.67 , which is generally regarded acceptable. Spearman rank correlation was used to quantify the association between patients' self-reported stress and satisfaction from joining the CCT. Ordinal logistic regression and logistic regression were used to analyse factors affecting the stress (moderate to severe stress vs 'mild stress' vs 'no stress at all') and satisfaction ( $\geq 9$ vs $<9$ ) of CCT participants.

\section{Patient and public involvement}

The questionnaire incorporated questions were conceived by the investigators without direct involvement of patient. There was no public involvement in this study.

\section{RESULTS}

Participants' demographics and trial characteristics

Among the 277 patients who were invited to participate, consent was obtained from 199 patients, with the response rate of $71.84 \%$ in our study. The demographics of the 199 participants and trial-related characteristics are presented in supplementary table 1 and supplementary table 2, respectively. Among the participants, more than half $(68.4 \%)$ of the participants had a high school or lower level of education, while 57 (28.6\%) participants had a university level of education. Most patient had lung cancer $(\mathrm{n}=87,43.7 \%)$, followed by breast cancer $(\mathrm{n}=35,17.6 \%)$, lymphoma $(\mathrm{n}=35,17.6 \%)$ and gastrointestinal tumours $(\mathrm{n}=12,6.0 \%)$. In terms of disease stage, $57(28.6 \%)$ patients answered early/limited stage; 123 $(61.8 \%)$ patients claimed advanced-staged or relapsed disease and the rest $19(9.5 \%)$ patients were not aware of their disease stage. A total of $177(88.9 \%)$ answered it was their first time participating in a CCT, while $22(11.1 \%)$ participants claimed several times of participation. There were $29(14.6 \%)$ manual workers and $97(48.7 \%)$ whitecollar workers. Nearly half of the participants $(46.2 \%)$ had a yearly household income of $<20000 ¥$ per person and only $14(7.0 \%)$ participants had an income of $>100000 ¥$, while $129(64.8 \%)$ had uninsured medical expenses for their cancer treatment of $>100000 ¥$. Median travel distance was $450.0 \mathrm{~km}$. Median time for travelling to the centre was 5.0 hours (IQR: 2.0-10.0 hours). There were $99(50.3 \%)$ participants in phase I studies, 17 (8.6\%) in phase II and $41(20.8 \%)$ in phase III. The number of participants who claimed they were not aware of the phase of the clinical trial they participated in was 33 (16.8\%).

\section{Participants' stress and satisfaction during trial participation} Stress evaluation and contributing factors analysis

Half of the participants $(52.3 \%)$ deemed there was no additional stress in clinical trial participation, while $22.1 \%$ $(n=44)$ participants claimed mild stress and $25.6 \%(n=51)$ patients claimed moderate or higher stress (figure 1). Perceived factors analysed via logistic regression were as follows: gender, age, cancer subtypes, time since cancer diagnosis, times of trial participation, types of study drug, study phase, prior uninsured medical expenses on cancer, marital status, education level, yearly household income per person, time consumption in trials, convenience of travelling and number of tests in CCT. Individuals with more prior medical costs $(\mathrm{OR}=1.23, \mathrm{p}=0.026)$, less time consumption in trial conduction $(\mathrm{OR}=2.35$, 


\begin{tabular}{llll}
$\begin{array}{l}\text { Table } 1 \\
\text { stress }\end{array}$ & Contributing factors of patients' self-assessed \\
\hline Parameter & OR & $\mathbf{9 5 \%} \mathbf{C l}$ & P value \\
\hline $\begin{array}{l}\text { Study phase } \\
\text { Other }\end{array}$ & 1.00 & - & \\
Phase I & 1.18 & 0.55 to 2.52 & 0.009 \\
$\quad$ Phase II & 0.29 & 0.10 to 0.90 & 0.032 \\
Phase III & 0.52 & 0.22 to 1.24 & 0.404 \\
Uninsured medical expenses & 1.23 & 1.03 to 1.46 & 0.026 \\
Time consumption & 2.35 & 1.62 to 3.41 & $<0.0001$ \\
Tests in trials & 0.64 & 0.42 to 0.97 & 0.035
\end{tabular}

$\mathrm{p}<0.0001)$ and more tests in CCT $(\mathrm{OR}=0.64, \mathrm{p}=0.035)$ were less likely to experience stress. Moreover, those participating in phase III studies bore less stress than phase II participants $(\mathrm{OR}=0.29, \mathrm{p}=0.032)$ but more stress than phase I participants $(\mathrm{OR}=1.18, \mathrm{p}=0.009)$ (table 1$)$.

\section{Satisfaction evaluation and contributing factors analysis}

A total of $147(73.9 \%)$ participants scored satisfaction $\geq 9 / 10 ; 52(26.1 \%)$ scored $<9 / 10 ; 17(8.5 \%)$ participants scored $\leq 6$. Patients' self-reported satisfaction was negatively associated with stress $(\mathrm{Rho}=-0.304, \mathrm{p}<0.0001)$. Perceived factors analysed via logistic regression were as follows: study phase, uninsured medical expenses on cancer, education level, yearly household income per person, impression on clinical practitioners, understanding of informed consent, enough time for decision-making before participation, convenience of travelling, number of tests in the clinical trial, time consumption in trial conduction and trial compensation. In the logistic regression analysis, enough time to decide on trial participation ( $\mathrm{OR}=0.36, \mathrm{p}=0.0003)$, better impression of doctors $(\mathrm{OR}=0.41, \mathrm{p}=0.047)$ and less time spent in the trial $(\mathrm{OR}=0.43, \mathrm{p}<0.0001)$ were positive factors of satisfaction (table 2). Financial compensation also seemed to be a positive factor $(\mathrm{OR}=0.83, \mathrm{p}=0.091)$, without statistical significance.

\section{Perception towards clinical trials and clinical practitioners}

Almost three-quarters of participants $(72.9 \%)$ claimed they had enough time to decide on trial participation and less than half $(47.2 \%)$ declared they had satisfactory compensation for their trial participation; $87.4 \%$ had a very positive impression of doctors; $73.9 \%$ claimed

\begin{tabular}{lllc|}
\hline $\begin{array}{l}\text { Table } 2 \text { Contributing factors of patients' self-assessed } \\
\text { satisfaction }\end{array}$ & OR & $\mathbf{9 5 \%} \mathbf{C l}$ & P value \\
\hline Parameter & 0.41 & 0.17 to 0.99 & 0.047 \\
\hline $\begin{array}{l}\text { Impression of clinical } \\
\text { practitioners }\end{array}$ & & & \\
Time for decision-making & 0.36 & 0.21 to 0.63 & 0.0003 \\
Time consumption & 2.31 & 1.53 to 3.48 & $<0.0001$ \\
Trial compensation & 0.83 & 0.66 to 1.03 & 0.091 \\
\hline
\end{tabular}

complete awareness of the trial in which they participated; $74.9 \%$ completely believe in the benefit of CCT; $21.1 \%$ agree with the positive impact of CCT; $3.5 \%$ felt themselves like guinea pigs and doubted the significance and scientific quality of the CCT; and $33.2 \%$ deemed the CCT time-consuming. Among the 199 participants, 147 $(83.9 \%)$ declared their willingness to join a CCT again; $95(47.7 \%)$ were concerned about the side effects of the experimentaltreatment they received and 31 (15.6\%) were worried about the too much time spent.

\section{DISCUSSION AND CONCLUSION \\ Discussion}

We conducted this study to gain an in-depth understanding about patients' subjective evaluation of stress and satisfaction in CCT, and explore potential factors impacting their stress and satisfaction. Our data also showed the perceptions of Chinese CCT participants and implicated possible measures to optimise patient satisfaction and ease the stress.

It has been indicated that having adequate time to make a final decision for trial participation could contribute to better collecting information of clinical trials and ensuring the ethical consent of participants. ${ }^{35}$ Our study showed that providing patients with subjectively enough time when making the decision to participate in a trial could also help with raising participants' satisfaction. In our view, time during informal decision-making reflects the time of medical staff providing information and the time of patient deliberation. Detailed information takes time, which allows patients to know more about the trial and treatment decisions, thereby reducing their pretreatment anxiety and raising participants' satisfaction. We suppose that patients should be provided with enough time as they need to organise their family and career in order to follow the trial schedule better. Physicians should suggest that patients take their time in decision-making before they sign the informed consent, which may not only help with enrolment but also with the patient adherence during the conduction of the trial.

Extra time, travel distance and transferring to another unit were significant patient barriers of patient participation. ${ }^{36-39}$ In our study, we assessed the distance and respective time spent during the conduction of the trial. Interestingly, time spent in the trial influenced participant-assessed satisfaction as well as stress. The median travel distance was $450.0 \mathrm{~km}$ and the median time spent travelling to the trial site was 5.0 hours. Participants with longer time consumption were less satisfied and more stressed. A less pleasant experience with respect to trial participation could impair others' perceptions. Actually, patients suffering the same disease always gather together online to discuss with each other on treatment options and encourage each other. If participants have a less pleasant experience with CCT participation due to any unpleasant experience during trial participation, it could have a negative impact on the impression of this trial for 
the potential trial participants, as well as on compliance of the patients under the study drug. Considering the broad area of China and the importance of individual's time, we conceived that it is necessary to inform patients of other trial sites and transfer the patient to their preferred site, in order to offer the patient with a option and optimise their experience in the conduction of a trial. Additionally, including some of the cost of travelling into the trial budget may encourage participation and optimise the evaluation of clinical trial participation. ${ }^{18}$

Socioeconomic status has been implicated as a factor correlated with clinical trial participation. ${ }^{19}$ Our data demonstrated the economic burden of the participants. In our study, only $7.0 \%$ of participants had a yearly household income of $>100000 ¥$ per person, while $64.8 \%$ had uninsured medical expenses for cancer treatment of $>100000 ¥$. This indicated that financial burden participants were bearing. Actually, in China, individuals saddled with a significant amount of out-of-pocket payments which is higher than those in most developed countries. According to the data from Organisation for Economic Co-operation and Development, roughly 29\% of healthcare expenses in China are paid by individuals, $30 \%$ by government funding and $41 \%$ by public and private insurance. ${ }^{40}$ Moreover, insurance benefits are distributed unevenly in China with limited and shallow insurance coverage in certain rural regions. Besides, owing to the underdeveloped primary healthcare system, patients prefer comprehensive hospitals instead of primary care facilities, leading to shift to certain hospitals and increased costs. Taking the abovementioned factors together, the cancer treatment could pose challenges on individuals, especially those have undergone several lines of treatment. Thus, participating in a clinical trial could relieve their financial burden to an extent. Interestingly, our study found that more tests in a trial are likely to lessen participants' stress, which could be related to financial burden as well, because patients rely on inpatient care to cover expenditure of tests. Indeed, in clinical trials, most tests are covered by sponsors which could relieve patients' financial burden.

Physicians have a major role in patient accrual, psychological status as well as evaluation towards CCT. Previous studies suggested that the doctor has a great influence on patient participation, suggesting that an affinity between doctor and patient can affect the conduct of a trial. In fact, in recent years, mistrust in medical staff and physical attacks on these professionals have become a common issue in China, ${ }^{41}$ which adds difficulties in medical communication, physician workloads and in turn escalating conflicts and disputes in a vicious circle. ${ }^{42}$ Considering the deteriorating doctor-patient relationship in China, addressing the impact of this relationship in the conduct of a trial is rather significant. Similar to the existing data, ${ }^{80-23}$ our study confirmed that a better impression of and confidence in doctors could add to patient satisfaction, which could optimise patient compliance and trial quality.
Patients' perceptions, stress and satisfaction may be influenced by the phase of trial in which they are participating. Our study demonstrated the correlation between study phase and patient stress in trial participation. Phase I studies are designed to evaluate the safety and pharmacology of a new treatment. Surprisingly, in our study, participants in phase I studies bore the least stress, probably because patients enrolled in phase I studies have failed standard treatment and the treatments available to them are limited. The knowledge of their disease status, lower expectation for treatment and the attention paid by physicians may contribute to lower self-reported stress during trial participation. However, in our study, participants in phase II bore the highest stress, which could potentially be correlated with their experimental nature. Moreover, the endpoint of phase II studies is to indicate efficacy, which results in a longer observation time compared with phase I studies. As a result, patients may feel more stressed in this study phase. In phase III studies, participants receive the treatments that have been proven safe and active in early phase trials, thus they bore less stress than those in phase II. However, they bore more stress than those in phase I studies. The reason for this could be multifactorial. Participants in phase III studies usually have standard treatment available. It has been indicated that random assignment and fear of receiving a placebo were potential barriers to clinical trials, as well as to patient psychological health. ${ }^{24}$ Besides, patients in phase III trial may face more nocebo effects and longer term of follow-ups than those in phase I trial.

Previous studies have addressed the perceptions of participants in $\mathrm{CCT}^{25} 28$ with generally positive perceptions. ${ }^{43-45}$ Similarly, in our study, only $3.5 \%$ of patients had negative view on the significance and scientific quality of clinical trial. Although the percentage is small, the fact that negative view might place mistrust and non-adherence during clinical trial participation still call for better education about the aims and rationale for the specific trial. Besides, although most participants claimed complete awareness of the participating trial, $16.8 \%$ of participants claimed not to be aware of the phase of the clinical trial they participated in. We conceived it is significant to expand the knowledge base and enhance knowledge with respect to CCT.

There were some limitations to this study. First, the cross-sectional design limited cause-and-effect conclusions and we cannot ignore recall bias in the follow-up survey part and the relatively subjective judgement of patient exclusion criteria. Second, considering patients always had psychological or quality-of-life questionnaire during trial participation, we developed a simplified study-specific scale to evaluate patients' stress and satisfaction instead of using recognised measures in the purpose of reducing patients' unwillingness. To better explore the contributing factors, a recognised scale is expected to evaluate patients' stress and satisfaction. Third, social desirability bias potentially existed because the questionnaire was delivered and retrieved in person, and patients may suppose that the 
researchers were hoping for a positive instead of honest responses. Additionally, the results of our study are limited to generalise to any broader population, because patients who declined to join our study were not surveyed and their perceptions and emotional burden could be different. Finally, this sample of trial participants all came from the same site. A multicentre survey is needed to test the generalisability of our findings.

\section{CONCLUSION}

To our knowledge, this is the first survey of emotional burden and affecting factors in CCT participants and it is the largest survey of the perceptions of Chinese participants in CCT. Thus, our study provides new and important information about the concerns of participants in Chinese CCT .

\section{Practice implications}

Studying the perceptions, stress and satisfaction of Chinese CCT patients has the potential to assist in recruiting more efficiently and improving patient experiences in the future.

\section{Author affiliations}

${ }^{1}$ Department of Medical Oncology, Beijing Key Laboratory of Clinical Study on Anticancer Molecular Targeted Drugs, National Cancer Center/National Clinical Research Center for Cancer/Cancer Hospital, Chinese Academy of Medical Sciences and Peking Union Medical College, Beijing, China

${ }^{2}$ National GCP Center for Anticancer Drugs, National Cancer Center/National Clinical Research Center for Cancer/Cancer Hospital, Chinese Academy of Medical Sciences and Peking Union Medical College, Beijing, China

Acknowledgements We also thank the members of the GCP Center of National Cancer Center/National Clinical Research Center for Cancer/Cancer Hospital, Chinese Academy of Medical Sciences and Peking Union Medical College for insightful suggestions.

Contributors YKShi and SYJ conceptualised and designed the study. YKShi, SYJ, PL, SY, JLY, DWW, HF, YQ, SYZ, JPX, YKSun, HNM, LG, PYX, BL, BZ and LT reviewed the literature, collected data and interpreted the findings. SYJ and YKShi performed statistical analysis and drafted the manuscript. All authors critically reviewed the manuscript and approved the final manuscript.

Funding This study was was supported by the grants from Chinese National Major Project for New Drug Innovation(2017ZX09304015).

Disclaimer The authors express sincere gratitude to the patients, their families and all investigators who participated in the study.

Competing interests None declared.

Patient consent for publication Obtained.

Ethics approval Ethical approval was obtained from the Institutional Review Board of National Cancer Center/National Clinical Research Center for Cancer/Cancer Hospital.

Provenance and peer review Not commissioned; externally peer reviewed.

Data sharing statement Dataset is available upon requirement.

Open access This is an open access article distributed in accordance with the Creative Commons Attribution Non Commercial (CC BY-NC 4.0) license, which permits others to distribute, remix, adapt, build upon this work non-commercially, and license their derivative works on different terms, provided the original work is properly cited, appropriate credit is given, any changes made indicated, and the use is non-commercial. See: http://creativecommons.org/licenses/by-nc/4.0/.

\section{REFERENCES}

1. PhIRDA. From imitator to innovator. Nature (supplement). https:// www.nature.com/collections/ssbnlhqwfc
2. Chen $\mathrm{W}$, Zheng R, Baade PD, et al. Cancer statistics in China. $C A$ Cancer J Clin 2016;66(2):115-132.

3. China Health and Family Planning Statistical Yearbook. Beijing: China Union Medical College Press, 2016.

4. Calderon C, Carmona-Bayonas A, Hernández R, et al. Effects of pessimism, depression, fatigue, and pain on functional health-related quality of life in patients with resected non-advanced breast cancer. Breast 2019;44:108-112.

5. Huang $\mathrm{Y}$, Huang $\mathrm{Y}, \mathrm{Bao} \mathrm{M}$, et al. Psychological resilience of women after breast cancer surgery: a cross-sectional study of associated influencing factors. Psychol Health Med 2019;5:1-13.

6. Lotfi-Jam K, Gough K, Schofield P, et al. A longitudinal study of four unique trajectories of psychological distress in cancer survivors after completing potentially curative treatment. Acta Oncol 2019;30:1-8.

7. Tate DG, Forchheimer M. Quality of life, life satisfaction, and spirituality: comparing outcomes between rehabilitation and cancer patients. Am J Phys Med Rehabil 2002;81:400-410.

8. Kleeberg UR, Tews JT, Ruprecht T, et al. Patient satisfaction and quality of life in cancer outpatients: results of the PASQOC study. Support Care Cancer 2005;13:303-310.

9. Gilbert SM, Dunn RL, Wittmann D, et al. Quality of life and satisfaction among prostate cancer patients followed in a dedicated survivorship clinic. Cancer 2015;121:1484-1491.

10. Amler $S$, Sauerland MC, Deiters $C$, et al. Factors influencing life satisfaction in acute myeloid leukemia survivors following allogeneic stem cell transplantation: a cross-sectional study. Health Qual Life Outcomes 2015;13:28

11. Bloomquist EV, Ajkay N, Patil S, et al. A randomized prospective comparison of patient-assessed satisfaction and clinical outcomes with radioactive seed localization versus wire localization. Breast $J$ 2016;22:151-157.

12. Arraras JI, Illarramendi JJ, Viudez A, et al. The cancer outpatient satisfaction with care questionnaire for chemotherapy, OUTPATSAT35 CT: a validation study for Spanish patients. Support Care Cancer 2012;20:3269-3278.

13. Dignan M, Evans $M$, Kratt $P$, et al. Recruitment of low income, predominantly minority cancer survivors to a randomized trial of the I Can Cope cancer education program. $J$ Health Care Poor Underserved 2011;22:912-924.

14. Blumenthal DS, Smith SA, Majett CD, et al. A trial of 3 interventions to promote colorectal cancer screening in African Americans. Cancer 2010;116:922-929.

15. Gooden KM, Carter-Edwards L, Hoyo C, et al. Perceptions of participation in an observational epidemiologic study of cancer among African Americans. Ethn Dis 2005;15:68-75.

16. Tabbarah M, Nowalk MP, Raymund M, et al. Barriers and facilitators of colon cancer screening among patients at faith-based neighborhood health centers. J Community Health 2005;30:55-74.

17. Cook ED, Arnold KB, Hermos JA, et al. Impact of supplemental site grants to increase African American accrual for the Selenium and Vitamin E Cancer Prevention Trial. Clin Trials 2010;7:90-99.

18. Sabesan S, Burgher B, Buettner P, et al. Attitudes, knowledge and barriers to participation in cancer clinical trials among rural and remote patients. Asia Pac J Clin Oncol 2011;7:27-33.

19. Unger JM, Hershman DL, Albain KS, et al. Patient income level and cancer clinical trial participation. J Clin Oncol 2013;31:536-542.

20. Corbie-Smith G, Viscoli CM, Kernan WN, et al. Influence of race, clinical, and other socio-demographic features on trial participation. J Clin Epidemiol 2003;56:304-309.

21. Mills EJ, Seely D, Rachlis B, et al. Barriers to participation in clinical trials of cancer: a meta-analysis and systematic review of patientreported factors. Lancet Oncol 2006;7:141-148.

22. Ross S, Grant A, Counsell C, et al. Barriers to participation in randomised controlled trials: a systematic review. J Clin Epidemiol 1999;52:1143-1156.

23. Verheggen FW, Nieman F, Jonkers R, et al. Determinants of patient participation in clinical studies requiring informed consent: why patients enter a clinical trial. Patient Educ Couns 1998;35:111-125.

24. Meropol NJ, Buzaglo JS, Millard J, et al. Barriers to clinical trial participation as perceived by oncologists and patients. J Natl Compr Canc Netw 2007;5:753-762.

25. Ellis PM, Butow PN, Tattersall MH, et al. Randomized clinical trials in oncology: understanding and attitudes predict willingness to participate. J Clin Oncol 2001;19:3554-3561.

26. Byrne MM, Tannenbaum SL, Glück S, et al. Participation in cancer clinical trials: why are patients not participating? Med Decis Making 2014;34:116-126.

27. Brown DR, Topcu M. Willingness to participate in clinical treatment research among older African Americans and Whites. Gerontologist 2003;43:62-72. 
28. Wood CG, Wei SJ, Hampshire MK, et al. The influence of race on the attitudes of radiation oncology patients towards clinical trial enrollment. Am J Clin Oncol 2006;29:593-599.

29. Zhao D, Zhang Z. Changes in public trust in physicians: empirical evidence from China. Front Med 2018. doi: 10.1007/s11684-018 0666-4. [Epub ahead of print]

30. Ending violence against doctors in China. Lancet 2012;345:25-27.

31. Yao S, Zeng Q, Peng M, et al. Stop violence against medical workers in China. J Thorac Dis 2014;6:E141-E145.

32. Wenzhi Cai, Ling Deng, Meng Liu, et al. Antecedents of medical workplace violence in South China. J Interpers Violence 2011;26:312-327.

33. Kibler JL, Brisco K, Dollar KM, et al. Prospective predictors of actual research participation among African-American adults. J Public Health 2014;22:271-275.

34. Bazarbashi S, Hassan A, Eldin AM, et al. Awareness and Perceptions of Clinical Trials in Cancer Patients and Their Families in Saudi Arabia. J Cancer Educ Off J Am Assoc Cancer Educ 2015;30:655-659.

35. Nakada H, Yoshida S, Muto K. "Tell me what you suggest, and let's do that, doctor": Patient deliberation time during informal decisionmaking in clinical trials. PLoS One 2019;14:e0211338.

36. Melisko ME, Hassin F, Metzroth L, et al. Patient and physician attitudes toward breast cancer clinical trials: developing interventions based on understanding barriers. Clin Breast Cancer 2005;6:45-54.
37. Ling J, Rees E, Hardy J. What influences participation in clinical trials in palliative care in a cancer centre? Eur J Cancer 2000;36:621-626.

38. LaVallie DL, Wolf FM, Jacobsen C, et al. Barriers to cancer clinical trial participation among Native elders. Ethn Dis 2008;18:210-217.

39. Ford JG, Howerton MW, Lai GY, et al. Barriers to recruiting underrepresented populations to cancer clinical trials: a systematic review. Cancer 2008;112:228-242.

40. OECD. Health spending (indicator, 2019. (Accessed 10 Feb 2019).

41. Jing $W$, Otten $H$, Sullivan $L$, et al. Improving the doctor-patient relationship in China: the role of balint groups. Int $J$ Psychiatry Med 2013;46:417-427.

42. Nie JB, Cheng Y, Zou X, et al. The vicious circle of patientphysician mistrust in China: health professionals' perspectives, institutional conflict of interest, and building trust through medical professionalism. Dev World Bioeth 2018;18:26-36.

43. Madsen SM, Mirza MR, Holm S, et al. Attitudes towards clinical research amongst participants and nonparticipants. J Intern Med 2002;251:156-168.

44. Bazarbashi S, Hassan A, Eldin AM, et al. Awareness and Perceptions of Clinical Trials in Cancer Patients and Their Families in Saudi Arabia. J Cancer Educ 2015;30:655-659.

45. Igwe E, Woodburn J, Davolos J, et al. Patient perceptions and willingness to participate in clinical trials. Gynecol Oncol 2016;142:520-524 